\title{
Innovative State Support for Economy of Rural Areas as Urban Satellites
}

\author{
B.V. Malozyomov \\ Novosibirsk State Technical University \\ Novosibirsk, Russian Federation \\ mbv5@mail.ru
}

\begin{abstract}
The paper proposes the social potential of rural areas. It gives the comparison of the quality of the population life of different countries through the criterion of expenditures and consumption of home economics. It also compares the rates of introduction of residential houses and improvement of housing stock, which demonstrated the growth of indicators in rural areas, as an evidence of their social potential growth. It states the theoretical substantiation of the necessity of attracting additional resources for the development of the socio-economic potential of the rural area and its structure. The motivation of the necessity of active involvement in the development of the territory of public organizations and the economic management system is also given here.
\end{abstract}

Keywords - rural area, social potential, social and economic potential, administrative potential, rural development programs.

\section{INTRODUCTION}

The circle of carriers and sources of replenishment of the social and economic potential of rural areas (as an unused reserve for its further development) is considered by the state and municipal government authorities as limited. Economic entities and bodies of territorial government are mainly considered as carriers. Means of budgets of all levels and economic participants of other projects are also considered. The purpose of the study is to identify the elements of the social potential of the territory that can create new goods and services. The objectives of the study included consideration of the social potential of rural areas as a consequence of the macroeconomic situation, the theoretical justification for the limited capacity of rural areas to develop its social and economic potential and to identify elements of administrative capacity that can create new goods and services. Methods of research are monographic, abstract-logical, statistical, comparison, analysis and synthesis.

The authors study the social and economic potential of the rural area as an aggregate of two components that have been sufficiently studied by modern science. The economic potential is an aggregate capacity of the subjects of socioeconomic activity within its borders, to produce material and non-material goods and services, to satisfy social needs, predicted and hidden resources and the conditions of their use [1]. Moreover, social potential is unrealized opportunities for the individual, from which the social potentials of different population groups are formed [2]. The most significant ones of these potentials are workers, youth and pensioners, entrepreneurial potential, the collective and the enterprise as a whole, the administrative potential of the municipal administration bodies including personal and collective potentials, the potential of the social infrastructure and the life support system.

\section{THEORY}

Each of these types of potential can be described by the indicators defined in the Report on the Sustainable Development of Rural Areas [3] and on the basis of RF Government Order No. 2336-r of 30.11.2010 "On Approving the Concept of Sustainable Development of Rural Territories of the Russian Federation for the Period to 2020".

In the opinion of the authors, the link in ensuring the effectiveness of using the economic potential is man as the carrier of the factor of production "labor" and its potential. The effectiveness of using other resources of the territory and their potentials, and ultimately its development depends on the extent to which it is used effectively and paid fairly for its work and what are the living conditions for a person (including how high its life support system is).

Therefore, one of the most important characteristics of social potential is the quality of life of the population, which in the globalized economy is largely determined by the level of the state economy development as a whole and its positioning relative to the economies of other countries. The authors' analysis of the growth rates of household expenditures showed that in Russia, they are outstripping world rates relative to all groups of states [1], which can not but affect the level and quality of the population life.

Comparable figures of actual final consumption of households in the Russian Federation were lower than in Turkey and the EU, but higher than in other CIS countries [4, 5]. 
TABLE I. DYNAMICS OF QUALITY OF LIFE INDICATORS OF URBAN AND RURAL POPULATION OF THE RUSSIAN FEDERATION

\begin{tabular}{|l|c|c|c|c|c|c|}
\hline \multicolumn{1}{|c|}{ Parameters } & 2011 & 2012 & 2013 & 2014 & 2015 & 2016 to 2018 \\
\hline \multicolumn{1}{|c|}{1} & 2 & 3 & 4 & 5 & 6 & 7 \\
\hline $\begin{array}{l}\text { 1. households were commissioned, million } \mathrm{m}^{2} \text { of total area, } \\
\text { total }\end{array}$ & 58.4 & 62.3 & 65.7 & 70.5 & 84.2 & 144.2 \\
\hline 1.1. in urban area & 43.7 & 46.8 & 50.0 & 53.0 & 62.2 & 142.3 \\
\hline 1.2. in the countryside & 14.7 & 15.5 & 15.7 & 17.5 & 22.0 & 149.7 \\
\hline 1.3. Share of rural areas in total, \% & 14.7 & 15.5 & 15.7 & 17.5 & 22 & 7.3 \\
\hline $\begin{array}{l}\text { 2. accomplishment of the housing stock, at the end of the } \\
\text { year, \% }\end{array}$ & & & & & & \\
\hline 2.1 plumbing installation, total & 137 & 139 & 139 & 142 & 140 & 3 \\
\hline 2.1.a. in urban area & 89 & 90 & 90 & 90 & 86 & -3 \\
\hline 2.1.b. in the countryside & 48 & 49 & 49 & 52 & 54 \\
\hline $\begin{array}{l}\text { 2.1.c. Share of rural areas in comparison with urban areas, } \\
\pm \%\end{array}$ & -41 & -41 & -41 & -38 & -32 \\
\hline
\end{tabular}

The growth in the rates of expenditure over the past five years has led to a decline in consumption, primarily of food products, the largest increase in the payment of transportation services. Moreover, the largest increase in this position was observed in the Siberian Federal District, as one of the most remote districts from the European part of Russia, on the one hand, and, on the other hand, like district, which does not have any significant preferences for tariffs for transportation and travel.

It is natural that the macroeconomic situation had a more destructive effect on the quality of life of the population in rural areas than of the urban population. In rural areas, the rate of housing construction is lower, the level of the construction with water supply, sanitation, heating, baths, hot water supply is 2-3 times lower, and electroflooring is 6 times lower (Table 1, lines 1.3, 2.1.c). Moreover, the difference in the share of housing in rural areas with respect to urban indicators is steadily declining, with the exception of the gasification index and the introduction of educational institutions, the gap in the provision of which is steadily increasing.

It should be noted that the rate of growth of indicators in rural areas is higher than of urban areas due to the availability of state support. The state has identified its interests in the development of the economy of rural areas as follows:

- creation of conditions for the resettlement of labor resources in the countryside;

- diversification of the economy of rural areas and expansion of sources of income generation for the rural population;

- rational involvement in economic circulation and increasing the efficiency of the use of natural, and, above all, land and recreational, material and labor resources of rural settlements;

- development of market infrastructure and increasing access of agricultural producers to the markets for products;

- strengthening state support for agricultural producers and increasing the social importance of rural workers;

- strengthening the scientific and professional component of the development of rural settlements $[6,7]$.

Essentially, the task is to develop the social and economic potential of rural areas and to create benefits for the population living there. However, the volume of goods produced is always limited by the capabilities (resources) of the system. The combination of the maximum volumes of the received goods can be represented in the form of a production capacity curve (Fig. 1). The points on the curve represent a situation where the entire socio-economic potential, characterizing the rural area, is used in its entirety.

Considering the socio-economic system from the point of view of the efficiency of using its potential, one assumes that the curve will show the optimal combination of economic and social benefits in a system in which it is impossible to increase the production of one good without a corresponding reduction of the other. It is in the Fig.1:

Y - social benefits (the volume of social payments and services provided to the population from the district budget or produced with its participation); 


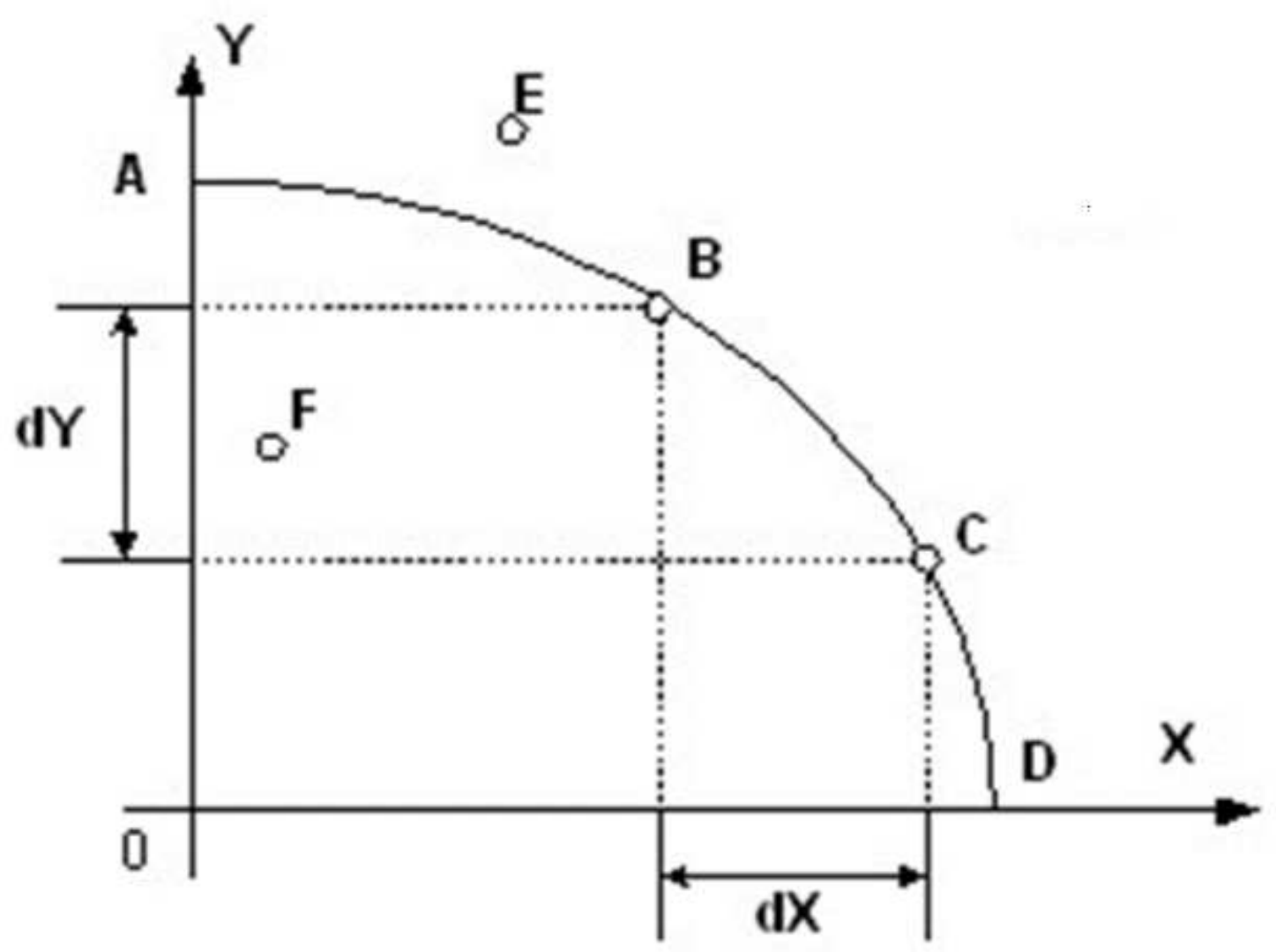

Fig. 1 - The ratio of economic and social benefits of the system

$\mathrm{X}$ - economic benefits (the volume of the created objects of production and market infrastructure and services rendered to the business, produced with the participation of the district budget);

A - all resources of the territory aimed at the production of social goods;

$\mathrm{B}$ and $\mathrm{C}$ - an effective combination, in which all economic and social resources are used;

D - the system resources aimed at the production of economic goods;

$\mathrm{F}$ - the point at which the use of system resources is not rational, that is, the potential of the socioeconomic system is not fully utilized;

E - the point at which available resources (carriers of potential) for a socio-economic system are not enough, and, therefore, it is not reachable. Economic theory defines two ways to achieve points $\mathrm{B}$ and $\mathrm{C}$ :

- intense, that is, increasing the efficiency of using the potential of the system using scientific and technological progress (expensive innovative technologies that involve the use of extra budgetary investors and budget development grants);

- extensive - due to the involvement of its own additional resources and budgetary resources to ensure simple reproduction of resources.

Above all, in both cases, funding is used from higher budgets, primarily within the framework of the State Program for the Development of Agriculture and Regulation of agricultural products, raw materials and foodstuffs for 20132020 years. The subprograms, included in it, provide for financing gasification and integrated development of settlements, provision of housing for young families and young specialists, and many other activities. Certain resources are allocated within the framework of regional small business development programs. And all of them are implemented on co-financing terms and require a deep project justification.

As a result, the growth rates of the introduction of residential buildings in recent years have changed in favor of the village by $7.4 \%$.

In this situation, the quality of the administrative potential of the rural area is of paramount importance, in which the authors offer to include the potential of individuals and the aggregate potential not only of the executive and legislative authorities of the territory, local self-government bodies and economic entities, but also of public organizations and bodies of economic management of the territory (Fig. 2).

Each of the elements of this system is able to make a 
significant contribution to the development of the social and economic potential of rural areas. But this requires streamlining communication channels between them, eliminating unnecessary links, achieving an optimal balance between the rights and responsibilities of individual state and municipal employees, structuring the administrative staff of economic entities of all forms of ownership of the territory.

In everyday practice of managing the territory, public movements, political attitudes of the population, and activities of non-profit organizations are not taken into account. These organizations do not find mutual understanding not only with official authorities but also with existing legislation in most territories. [8]. Despite these trends, the impact of non-profit organizations is often an important tool for interaction between the active part of the population and the administrative structures of the territories.

The lack of social orders negatively affected the part of the executive authorities of non-profit organizations, allowing one to delegate some of the social burden from the budgets of the territories. The problem of using the resource of non-profit organizations to increase the administrative potential of rural areas is the low social initiative of the population of rural areas. Despite the large number of public associations and political parties at the regional level, the level of legislative initiative remains at the level of rural areas, the Public Councils of the territories, which in its majority are a formal body under the administrations of municipalities.

But it is civil initiatives, civil control that can influence the formation of the foundations of the rule of law, the universal observance of the rule of law, the protection of human rights and the prevention of corruption, the most acute problems, hampering the development of territorial systems of the regional and municipal level and the country as a whole. By using the potential of public organizations and civil structures, the administrative potential of the territory rises and, as a consequence, its social and economic potential, transparency of state and municipal management are achieved, and as a result, the level of citizens' confidence in institutions of power increases.

In the rural territories, they did not receive the

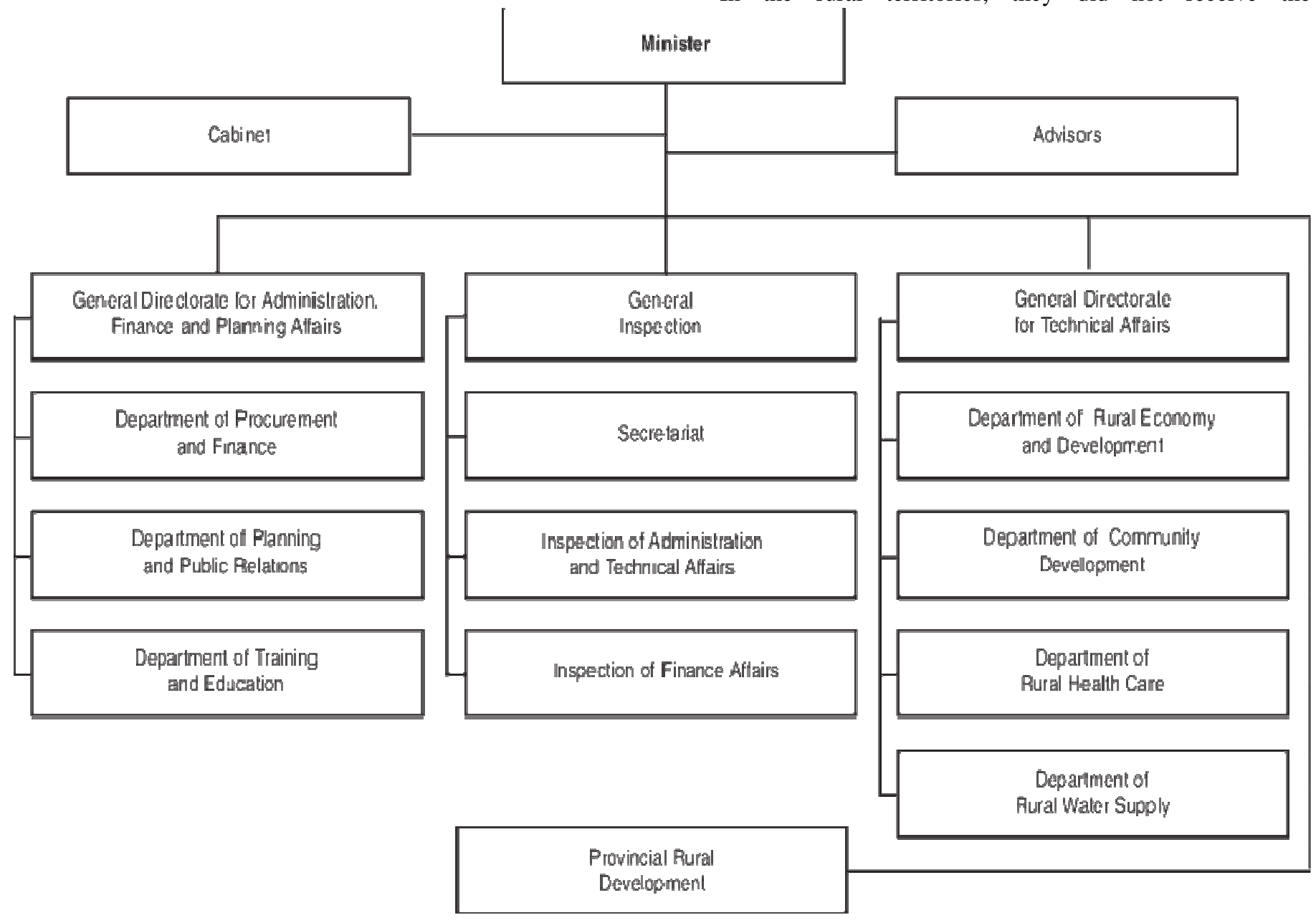

Fig. 2. Structure of the administrative potential of rural areas 
development of associations of entrepreneurs, actively working in certain sectors of the economy, cities and regional centers. The economic councils created at the heads of the districts are often formal and do not take part in solving the fundamental issues of budget allocation [8]. Moreover, associations of entrepreneurs are generally considered inefficient due to the dispersal of rural settlements. Activating the work of these structures will make it possible not only to make open decisions, taken by district government bodies, but also to direct the initiative and attract funds from citizens and the business community to address the most pressing social problems in the village [9].

\section{CONCLUSION}

The quality of the social potential in the globalized economy is largely determined by the level of development of the state economy. The reflection of this level is growth rates of household, which in Russia outstrips global rates. Indicators of actual final consumption of households in Russia are lower than in the US, Turkey and the EU. The increase in the rate of expenditure over the past five years has primarily led to the decline of food and transportation costs. The quality of the population life in rural areas is much lower than that of urban areas: the level of housing construction with water supply, sanitation, heating, baths, hot water supply is 2-3 times lower, and electroflooring is 6 times lower. The rates of growth of indicators are much higher (except for gasification and the construction of educational institutions), which is associated with the implementation of programs to support the development of rural areas based on co-financing projects. The increase of the effective use of budget funds at all levels is possible only in case of maximum involvement of the administrative potential of the territory. The authors propose including into the administrative potential the potential of the personality of people within the structure bodies of management of the territory, the aggregate potential of government bodies, local self-government bodies, public organizations and economic territorial subjects. Each of these elements will create new social benefits, increasing the social and economic potential of the territory.

\section{References}

[1] S. Barkova, "Personnel management", Novosibirsk, p. 46, 2001.

[2] L.M. Galiev "Investigation of the concept of "potential" and "social potential" in sociology Advanced Materials Research, Vol. 1040, pp. 778-783, 2014.

[3] K.C. Akberov, B.V Malozyomov, "Optimization of production factors in the structure of the social and economic potential of the rural area", Information technologies in science, management and education: materials for correspondence. All-Russia. Scientific-practical. Conf., Dedicated. 60 years of Sib. Un-ta need. Co-op., Novosibirsk, March 1418, 2016. Novosibirsk: Sib. Un-t consumption. Co-op., pp. 70-77, 2016.

[4] V.V. Biryukov and A.V. Kulekina, "The calculation features of the electrical energy storage devices parameters in transport", The 11 International forum on strategic technology (IFOST 2016), pp. 41-43, 2016.

[5] N.I. Schurov, E.A. Spiridonov and A.V Larin, "Modes of traction power supply system in case of electric rolling stock equipped with energy storage", Applied Mechanics and Materials, 2014, Vol. 698, pp. 19-23.
[6] Photovoltaic (PV) research: National Renewable Energy Laboratory (NREL). Retrieved on http://www.nrel.gov/ncpv.

[7] Babashkina A.M. "State regulation of the national economy: Textbook. Allowance", Ekaterinburg: "USURT Press", pp. 116-119, 2006.

[8] G.M. Gritsenko, "Methods and mechanisms for assessing the economic potential of the agrosocial system of the municipal district Russia and the APR countries: historical experience of agrarian development", mater. Y Int. Scientific-practical. Conf., Dedicated. 150th anniversary of the birth of P.A. Stolypin (Blagoveshchensk, April 4-5, 2012), pp. 145149, 2012.

[9] G.M. Gritsenko and A.N. Lukyanov, 'Is it possible to effectively manage the agricultural enterprise in the conditions of democratization of the rural community?", The Economy of Agricultural and Processing Enterprises, Vol. 11, pp. 17-23, 2007.

[10] B.V. Malozyomov, K. Ch. Akberov, "On the synthesis of the algorithm for assessing the socio-economic system.", Information technology in science, management and educa tion: materials for. All-Russia. Scientific-practical. Conf., Dedicated. 60 years of Sib. Un-ta need. Coop., Novosibirsk, March 14-18, Novosibirsk: Sib. Un-t consumption. Co-op., pp. 11-15, 2016. 